\section{Incomplete Dominance of Rust Resistance in Tepary Bean}

\author{
Phillip N. Miklas ${ }^{1}$ \\ U.S. Department of Agriculture, Agricultural Research Service, Irrigated \\ Agriculture and Extension Center, 24106 North Bunn Road, Prosser, \\ WA 99350-9687
}

\section{J. Rennie Stavely ${ }^{2}$}

U.S. Department of Agriculture, Agricultural Research Service, Molecular Plant Pathology Laboratory, Room 252, Building 011A, 10300 Baltimore Avenue, Baltimore, MD 20705-2350

\section{Additional index words. Phaseolus acutifolius, Uromyces appendiculatus, genetics}

Abstract. Foliar diseases are a major constraint to cultivated tepary bean (Phaseolus acutifolius A. Gray var. latifolius Freeman) production in some environments. The reactions of 12 cultivated teparies to eight individual races $(41,47,49,51,53,58,67$, and 73) of the bean rust fungus Uromyces appendiculatus (Pers.) Unger var. appendiculatus maintained at Beltsville, Md., were examined under greenhouse conditions. These diverse races, used together, overcome all of the major rust-resistance genes present within the 19 host differential cultivars of common bean (Phaseolus vulgaris L.). Seven lines (GN-605s, GN-610-s, PI 321638-s, PI 502217-s, Neb-T-6-s, Neb-T-8a-s, and Neb-T-15-s) exhibited similarly high levels of resistance (immunity or necrotic spots without sporulation) to all eight races. Inheritance of resistance was examined across five susceptible $\times$ resistant $(S$ $\times R)$ and three resistant $\times$ resistant $(R \times R)$ populations. The rust reactions in the $F_{1}, F_{2}$, and $F_{3}$ generations derived from $S \times R$ crosses revealed that the immune or necrotic resistance response was conditioned by a single locus exhibiting incomplete dominance. The rust resistance of four lines tested for allelism in $R \times R$ crosses was found to be derived from the same gene. This apparent lack of variability for rust resistance suggests that a single introgression event may realize the full potential for cultivated tepary bean to contribute rust resistance to common bean through interspecific hybridization. In addition, the limited variability for resistance to the highly variable rust pathogen in cultivated tepary bean supports the occurrence of a "bottleneck effect" during domestication of this species, as observed in germplasm diversity studies.

The cultivated tepary bean, an annual desert legume indigenous to Mexico and the southwestern United States, is adapted to heat and drought stress and has resistance or tolerance to many diseases (Kaiser, 1981; Miklas and Santiago, 1996; Miklas et al., 1994, 1997; Pratt and Nabhan, 1988; Salgado et al., 1994; Thomas et al., 1983). For these reasons, both production of tepary bean in arid and semiarid regions of the world, and its use as a donor of useful traits to common bean through interspecific hybridization, have received considerable attention.

Honma (1956) and others (McElroy, 1985; Scott and Michaels, 1992) have successfully transferred resistance to common bacterial blight [Xanthomonas campestris pv. phaseoli (Smith) Dye] from tepary to common bean. Resistance to bean rust in some tepary bean lines has been observed in Puerto Rico (Kaiser, 1981; Miklas et al., 1994); however, its

Received for publication 29 Apr. 1997. Accepted for publication 23 July 1997. The cost of publishing this paper was defrayed in part by the payment of page charges. Under postal regulations, this paper therefore must be hereby marked advertisement solely to indicate this fact.

${ }^{1}$ Research Geneticist.

${ }^{2}$ Research Plant Pathologist. resistant to susceptible (Miklas et al., 1994), and investigated the inheritance of the resistance reaction in various crosses among these lines.

\section{Materials and Methods}

Resistance to bean rust and its inheritance was evaluated across 12 cultivated tepary bean lines: GN-605-s, GN-610-s, PI's 321637-s, 321638-s, 440788-s, 440806-s, 502217-s, NebT-1-s, Neb-T-5-s, Neb-T-6-s, Neb-T-8a-s, and Neb-T-15-s. Agronomic characteristics and field reactions for 11 of these lines to rust and other diseases were reported previously (Miklas and Santiago, 1996; Miklas et al., 1994). The field rust reaction of Neb-T-5-s, although previously unreported, was susceptible. The 12 tepary lines and the rust-susceptible $P$. vulgaris dry bean pinto 'UI-114' were inoculated with eight individual $U$. appendiculatus races, $41,47,49,51,53,58,67$, and 73 , that are maintained by the U.S. Dept. of Agriculture, Agricultural Research Service, at
Beltsville, Md. These diverse races were selected because, when used together, they detect and overcome all of the major bean rust resistance genes in the 19 host differential cultivars of common bean (Stavely, 1984a; Stavely and Batra, 1991; Stavely et al., 1989).

Individual plants were inoculated in the greenhouse with each race singly, four races on each unifoliolate leaf, 5 to $7 \mathrm{~d}$ after planting. Inoculum preparation and application, and subsequent conditions for incubation of inoculated plants followed the protocol of Stavely (1983). Rust reaction was graded $10 \mathrm{~d}$ after inoculation using a 1 to 6 scale (Stavely et al., 1983), where $1=$ an immune response having no visible symptoms, 2 = necrotic spots without sporulation, $3=$ uredinia $<0.3 \mathrm{~mm}$ in diameter, $4=$ uredinia 0.3 to $0.5 \mathrm{~mm}, 5=$ uredinia 0.5 to $0.8 \mathrm{~mm}$, and $6=$ uredinia $>0.8$ $\mathrm{mm}$ in diameter. Generally, a score of 1 to 3 is considered a resistant reaction and 4 to 6 susceptible.

The inheritance of resistance to the eight rust races was evaluated across eight $F_{2}$ populations, with five derived from crosses between rust-susceptible and resistant lines [NebT-15-s ( $\mathrm{R}=$ resistant $) / \mathrm{Neb}-\mathrm{T}-1$-s $(\mathrm{S}=$ susceptible); Neb-T-5-s (S)/Neb-T-6-s (R); Neb-T1-s (S)/GN-610-s (R); PI 321637-s (S)/NebT-8a-s (R); and PI 321637-s (S)/PI 321638-s (R)] and three derived from crosses between resistant lines to test for allelism [Neb-T-6-s (R)/Neb-T-8a-s (R); Neb-T-6-s(R)/PI 321638s (R); and PI 321638-s (R)/GN-610-s (R)]. A variable number of $F_{2}$ plants ranging from 22 to 50 individuals were inoculated from each population. For some crosses, the rust reaction of $F_{1}$ plants [Neb-T-5-s (S)/Neb-T-6-s (R); Neb-T-1-s (S)/GN-610-s (R); PI321637-s (S)/ PI 321638-s (R); Neb-T-6-s (R)/Neb-T-8a-s (R); Neb-T-6-s (R)/PI 321638-s (R)] and $F_{3}$ progenies [Neb-T-15-s (R)/Neb-T-1-s (S); Neb-T-1-s (S)/GN-610-s (R)] were also evaluated. Segregation ratios were analyzed using chi-square tests $\left(\chi^{2}\right)$.

\section{Results and Discussion}

Of the 12 cultivated bean lines tested, seven were resistant, one had a mixture of resistant and susceptible plants, and four were susceptible (Table 1). Only PI 321638-s showed a different reaction between the field (susceptible) and the greenhouse (resistant) (Miklas et al., 1994). Lines susceptible to one race were equally susceptible to the other seven races, and lines resistant to one race were also resistant to the other seven races, but with occasional slight differences in the degree of resistance. Lines expressing resistance had either an immune (grade 1) or faint necrotic spot (grade 2) reaction, but an occasional small grade 3 pustule reaction was observed. Susceptible lines exhibited large pustule reactions (grade 6), but usually some smaller pustule sizes (grades 4 and 5) were intermixed with grade 6 reactions on the inoculated leaves.

The eight rust races caused a few differential reactions among the resistant lines (Table 1). For instance, GN-605-s and PI 321638-s are distinguished by their reactions to races 41 
(grade 2 vs. 1) and 67 (grade 1 vs. 3). Differential reactions like these, although slight, still suggest that some lines may contain unique rust resistance alleles or genes, or additional genes having minor effects.

Within each $\mathrm{S} \times \mathrm{R}$ derived $\mathrm{F}_{2}$ population, in addition to individuals expressing either the uniformly resistant (grades 1 and 2, with some 3 ) or susceptible (grade 6, with some 4 and 5) parental reactions to each of the eight races, there were individuals that expressed an intermediate response consisting predominantly of a grade 3 reaction, with some grades 2 and 4 intermixed (Table 2). The three reaction classes segregated $1: 2: 1$ in each of the $F_{2}$ populations, with the intermediate grade 3 reaction prevalent in the heterozygous class $(50 \%)$, and the parental grades 1 and 2, and grades 5 and 6 prevalent in the homozygous resistant (25\%) and susceptible (25\%) classes, respectively. The 1:2:1 segregation ratios revealed that the resistance within GN-610-s, Neb-T-6-s, NebT-8a-s, Neb-T-15-s, and PI 321638-s was conditioned by a single gene; however, the number of individuals screened within the $\mathrm{F}_{2}$ populations was probably too small to detect crossovers within a series of tightly linked genes.

The $F_{1}$ and $F_{3}$ segregation data support the $\mathrm{F}_{2}$ hypothesis of a single resistance gene (grades 1 and 2) having incomplete or partial expression when in the heterozygous condition (Tables 2 and 3 ). All the available $F_{1}$ plants from $S \times R$ crosses that were inoculated had an intermediate grade 3 reaction to the eight races. The $\mathrm{F}_{3}$ progenies from $\mathrm{F}_{2}$ plants with either immune/hypersensitive or susceptible reactions bred true, while progenies from $\mathrm{F}_{2}$ plants with intermediate grade 3 reactions segregated 1:2:1 [grades $1-2(25 \%)$ : grade $3(50 \%)$ : grades 5-6 (25\%)]. This incomplete dominance for the immune resistance in tepary bean deviates from the complete dominance expressed by rust resistance genes in common bean (Grafton et al., 1985; Stavely, 1984b).

The lack of segregation for susceptibility or the intermediate grade 3 reaction in $F_{1}$ or $F_{2}$ plants from $R \times R$ crosses indicates that the rust resistance within GN-610-s, Neb-T-6-s, Neb-T-8a-s, and PI 321638 is likely derived from the same gene (Table 2). This lack of genetic variability for rust resistance within cultivated tepary bean may result from the pronounced "bottleneck effect" that Schinkel and Gepts (1988) and Garvin and Weeden (1994) suggested may have occurred during the domestication of this species. In fact, a single domestication event for this species is supported by extensive phaseolin (Schinkel and Gepts, 1988) and isozyme (Garvin and Weeden, 1994) diversity observed among wild forms, compared with little or no variation among cultivated accessions.

In summary, the observed resistance within these cultivated tepary bean lines should be effective against most rust races that occur in the temperate United States and against many that occur in tropical environments. However, the resistance gene was not challenged by all of the most virulent races from Central America. Little if any genetic variability existed among at least four of the seven rust-
Table 1. Rust reaction ${ }^{2}$ of 12 cultivated tepary bean lines and a dry bean check pinto 'UI-114' inoculated with eight races of Uromyces appendiculatus.

\begin{tabular}{lccccccccr}
\hline & No. & \multicolumn{7}{c}{ Bean rust race } \\
\cline { 2 - 10 } Line & plants & 41 & 47 & 49 & 51 & 53 & 58 & 67 & 73 \\
\hline GN-605-s & 16 & 2 & 1 & 1 & 1 & 1 & 1 & 1 & 1 \\
GN-610-s & 18 & 2 & 2 & 2 & 2 & 1 & 1 & 2 & 1 \\
PI 321637-s & 11 & 6 & 5 & 6 & 6 & 6 & 6 & 6 & 5 \\
PI 321638-s & 18 & 1 & 1 & 1 & 1 & 1 & 1 & 3 & 1 \\
PI 440788-s & 7 & 1 & 1 & 1 & 1 & 1 & 1 & 1 & 1 \\
& 9 & 6 & 6 & 6 & 6 & 6 & 6 & 6 & 6 \\
PI 440806-s & 14 & 6 & 6 & 6 & 6 & 6 & 6 & 6 & 6 \\
PI 502217-s & 16 & 1 & 2 & 2 & 1 & 1 & 1 & 1 & 1 \\
Neb-T-1-s & 18 & 6 & 6 & 6 & 6 & 6 & 6 & 6 & 6 \\
Neb-T-5 & 12 & 6 & 6 & 6 & 6 & 6 & 6 & 6 & 6 \\
Neb-T-6-s & 18 & 2 & 2 & 2 & 2 & 1 & 2 & 2 & 2 \\
Neb-T-8a-s & 18 & 2 & 3 & 2 & 2 & 2 & 2 & 2 & 2 \\
Neb-T-15-s & 18 & 2 & 3 & 1 & 1 & 2 & 2 & 3 & 1 \\
UI-114 & 4 & 6 & 6 & 6 & 6 & 6 & 6 & 6 & 6 \\
\hline
\end{tabular}

${ }^{2} \mathrm{~A}$ predominant rust grade of $1=$ immune response; $2=$ necrotic spots without sporulation; $3=$ uredinia $<0.3$ mm in diameter; $4=$ uredinia 0.3 to $0.5 \mathrm{~mm} ; 5=$ uredinia 0.5 to $0.8 \mathrm{~mm}$; and $6=$ uredinia $>0.8 \mathrm{~mm}$ in diameter (Stavely et al., 1983). Only the predominant grade is given here, but often a grade of 3 may also occur with some grade 2, nonsporulating responses, and a grade 6 often occurs with some grade 5 uredinia.

${ }^{y}$ This line had a mixture of rust-resistant and susceptible plants.

Table 2. Segregation for resistance to eight rust races in the $F_{1}$ and $F_{2}$ generations derived from crosses between rust-resistant and susceptible cultivated tepary bean lines.

\begin{tabular}{|c|c|c|c|c|c|}
\hline \multirow[b]{2}{*}{ Population } & \multicolumn{3}{|c|}{ Rust reaction grade ${ }^{z}$} & \multirow[b]{2}{*}{$\begin{array}{c}\chi^{2} \\
1: 2: 1 \\
\end{array}$} & \multirow[b]{2}{*}{$P$} \\
\hline & $1-2$ & $\begin{array}{r}3 \\
\text { (no. of p }\end{array}$ & $5-6$ & & \\
\hline \multicolumn{6}{|c|}{ Crosses between susceptible $(S)$ and resistant $(R)$ lines } \\
\hline \multicolumn{6}{|l|}{$F_{1}$} \\
\hline Neb-T-5-s(S)/Neb-T-6-s(R) & 0 & 3 & 0 & & \\
\hline PI 321637-s(S)/PI 321638-s(R) & 0 & 1 & 0 & & \\
\hline Neb-T-8-s(R)/PI 440788-s(S) & 0 & 2 & 0 & & \\
\hline \multicolumn{6}{|l|}{$F_{2}$} \\
\hline Neb-T-5-s(S)/Neb-T-6-s(R) & 6 & 11 & 5 & 0.1 & $>0.95$ \\
\hline PI 321637-s(S)/PI 321638-s(R) & 8 & 26 & 8 & 2.4 & $>0.30$ \\
\hline PI 321637-s(S)/Neb-T-8a-s(R) & 10 & 15 & 5 & 1.7 & $>0.30$ \\
\hline Neb-T-1-s(S)/GN-610-s(R) & 5 & 10 & 8 & 0.3 & $>0.80$ \\
\hline Totals $^{y}$ & 29 & 62 & 26 & 0.5 & $>0.70$ \\
\hline Neb-T-15-s(R)/Neb-T-1-s(S) & 11 & 34 & 13 & 1.9 & $>0.30$ \\
\hline
\end{tabular}

$F_{1}$

$\begin{array}{lrll}\text { Neb-T-6-s/PI 321638-s } & 2 & 0 & 0 \\ \text { Neb-T-6-s/Neb-T-8a-s } & 7 & 0 & 0 \\ \text { Neb-T-6-s/PI 321638-s } & 42 & 0 & 0 \\ \text { Neb-T-6-s/Neb-T-8a-s } & 61 & 0 & 0 \\ \text { PI 321638-s/GN-610-s } & 65 & 0 & 0 \\ \text { Totals } & 168 & 0 & 0\end{array}$

${ }^{2}$ Rust reactions represent the predominant grades across the eight races $(41,47,49,51,53,58,67$, and 73$)$ as individual $F_{2}$ plants were either uniformly resistant, intermediate, or susceptible to all the races (i.e., no recombination events were detected).

${ }^{y}$ The heterogeneity interaction $\chi^{2}$ test, $4.7 P>0.30$, indicated homogeneity among families.

${ }^{x}$ This $F_{2}$ population is listed separately because the Neb-T-15-s resistance was not tested for allelism with the other resistance genes.

Table 3. Segregation for resistance to eight rust races in $\mathbf{F}_{2: 3}$ progenies derived from crosses between rustresistant and susceptible cultivated tepary bean lines.

\begin{tabular}{|c|c|c|c|c|c|c|}
\hline \multirow[b]{2}{*}{ Population } & \multirow{2}{*}{$\begin{array}{c}\mathrm{F}_{3} \\
\text { progenies } \\
\text { (no.) }\end{array}$} & \multicolumn{3}{|c|}{ Rust reaction grade $^{z}$} & \multirow[b]{2}{*}{$\begin{array}{c}\chi^{2} \\
1: 2: 1\end{array}$} & \multirow[b]{2}{*}{$P$} \\
\hline & & $1-2$ & $\begin{array}{c}3 \\
\text { (no. of } F_{3} \text { plants) } \\
\end{array}$ & $\overline{5-6}$ & & \\
\hline \multicolumn{7}{|c|}{$N e b-T-15-s(R) / N e b-T-I-s(S)$} \\
\hline$F_{2}(\text { grade })^{y}: F_{3}$ & 3 & 25 & 39 & 20 & 0.9 & $>0.50$ \\
\hline$F_{2}$ (grades 1,2$): F_{3}$ & 1 & 30 & 0 & 0 & & \\
\hline$F_{2}($ grades 5,6$): F_{3}$ & 1 & 0 & 0 & 3 & & \\
\hline \multicolumn{7}{|c|}{$N e b-T-1-s(S) / G N-610-s(R)$} \\
\hline $\mathrm{F}_{2}($ grade 3$): \mathrm{F}_{3}$ & 2 & 9 & 17 & 8 & 0.1 & $>0.95$ \\
\hline
\end{tabular}

${ }^{2}$ Rust reactions represent the predominant grades across the eight races $(41,47,49,51,53,58,67$, and 73$)$, as individual $F_{2: 3}$ plants were either uniformly resistant, intermediate, or susceptible to all the races. ${ }^{y}$ Indicates the rust reaction of the $F_{2}$ plant from which the $F_{3}$ progeny was derived. 
resistant lines that were tested for allelism. Thus, a single introgression event may realize the full potential for GN-610-s, PI 321638-s, Neb-T-6-s, Neb-T-8a-s, and perhaps other cultivated tepary bean to contribute rust resistance to common bean through interspecific hybridization. The limited variability we observed for rust resistance, as predicted by Garvin and Weeden (1994) and Schinkel and Gepts (1988), suggests that a survey for further variability for rust resistance in this species should focus on wild teparies ( $P$. acutifolius var. tenuifolius) sampled across a broad geographic range.

\section{Literature Cited}

Garvin, D.F. and N.F. Weeden. 1994. Isozyme evidence supporting a single geographic origin for domesticated tepary bean. Crop Sci. 34:13901395.

Grafton, K.F., G.C. Weiser, L.J. Littlefield, and J.R Stavely. 1985. Inheritance of rust resistance to two races of leaf rust in dry edible bean. Crop Sci. 25:537-539.

Honma, S. 1956. A bean interspecific hybrid. J. Hered. 47:217-220.

Kaiser, W.J. 1981. Diseases of chickpea, lentil, pigeon pea, and tepary bean in continental United States and Puerto Rico. Econ. Bot. 35:300-320.

McElroy, J.B. 1985. Breeding dry beans, Phaseolus vulgaris $\mathrm{L}$., for common bacterial blight resistance derived from Phaseolus acutifolius A. Gray. PhD Diss., Cornell Univ., Ithaca, N.Y.

Miklas, P.N., J.C. Rosas, J.S. Beaver, L. Telek, and G.F. Freytag. 1994. Field performance of select tepary bean germplasm for the tropics. Crop Sci. 34:1639-1644.

Miklas, P.N. and J. Santiago, 1996. Reaction of select tepary bean to bean golden mosaic virus. HortScience 31:430-432.

Miklas, P.N., H.F. Schwartz, M.O. Salgado, R. Nina, and J.S. Beaver. 1998. Reaction of select tepary bean to ashy stem blight and fusarium wilt. HortScience 33:136-139.

Pratt, R.C. and G.P. Nabhan. 1988. Evolution and diversity of Phaseolus acutifolius genetic re sources, p. 409-440. In: P. Gepts (ed.). Genetic resources of Phaseolus beans. Kluwer Academic Publishers, Dordrecht, The Netherlands.

Salgado, M.O., H.F. Schwartz, M.A. Brick, and M.A. Pastor-Corrales. 1994. Resistance to Fusarium oxysporum f. sp. phaseoli in tepary bean (Phaseolus acutifolius). Plant Dis. 78:357360.

Schinkel, C. and P. Gepts. 1988. Phaseolin diversity in the tepary bean, Phaseolus acutifolius A.
Gray. Plant Breeding 101:292-301.

Scott, M.E. and T.E. Michaels. 1992. Xanthomonas resistance of Phaseolus interspecific cross selection confirmed by field performance. HortScience 27:348-350.

Stavely, J.R. 1983. A rapid technique for inoculation of Phaseolus vulgaris with multiple pathotypes of Uromyces phaseoli. Phytopathology 73:676-679.

Stavely, J.R. 1984a. Pathogenic specialization in Uromyces phaseoli in the United States and rust resistance in beans. Plant Dis. 68:95-99.

Stavely, J.R. 1984b. Genetics of resistance to Uromyces phaseoli in a Phaseolus vulgaris line resistant to most races of the pathogen. Phytopathology 74:339-344.

Stavely, J.R. and L.R. Batra. 1991. Recently identified new pathogenic variability in Uromyces appendiculatus. Phytopathology 81:704. (Abstr.)

Stavely, J.R., G.F. Freytag, J.R. Steadman, and H.F. Schwartz. 1983. The 1983 bean rust workshop. Annu. Rpt. Bean Improv. Coop. 26:iv-vi.

Stavely, J.R., J.R. Steadman, and R.T. McMillan, Jr. 1989. New pathogenic variability in Uromyces appendiculatus in North America. Plant Dis. 73:428-432.

Thomas, C.V., R.M. Manshardt, and J.G. Waines. 1983. Teparies as a useful source for improving common beans. Desert Plants 5:43-48. 